Research Article

\title{
Prevalence and Associated Factors of Nonexclusive Breastfeeding to Infants within the First 6 Months in Gondar Town, Northwest Ethiopia, 2014
}

\author{
Mengistu Berhanu, ${ }^{1}$ Workie Zemene, ${ }^{2}$ and Mengistu Mekonnen ${ }^{2}$ \\ ${ }^{1}$ Department of Nursing, Teda Health Science College, 790 Gondar, Ethiopia \\ ${ }^{2}$ Department of Nursing, Gondar College of Medicine and Health Sciences, UoG, 196 Gondar, Ethiopia \\ Correspondence should be addressed to Mengistu Mekonnen; mesyfikir21@gmail.com
}

Received 27 December 2014; Revised 16 February 2015; Accepted 3 March 2015

Academic Editor: Ann M. Mitchell

Copyright ( $) 2015$ Mengistu Berhanu et al. This is an open access article distributed under the Creative Commons Attribution License, which permits unrestricted use, distribution, and reproduction in any medium, provided the original work is properly cited.

Introduction. Nonexclusive breastfeeding (NEBF) is giving infants other foods or fluids in addition to the breast milk within the first six months of age. According to Ethiopian Demographic and Health Survey 2011, prevalence of NEBF was found to be 48\%; this has a great impact on the health and development of the child. Objectives. To assess the prevalence and associated factors of NEBF to infants within the first six months. Methods. Community based cross-sectional study design was employed from March 1 to 31, 2014, among 828 mothers with infants 6 to 12 months old. Systematic random sampling technique was used to select study subjects. Logistic regression analysis with $95 \%$ CI was computed to identify predictor variables. Result. A total of 828 mothers with infants aged between 6 and 12 months were interviewed with 100\% response rate. Prevalence of NEBF was $47.5 \%$. Mothers who completed primary school (AOR $=0.46$ [95\% CI: $0.30,0.71]$ ) were less likely practicing NEBF compared to mothers with no formal education. Governmental employees (AOR $=2.55$ [95\% CI: 1.45, 4.46]) were more likely practicing NEBF. Conclusion. NEBF was practiced by $47 \%$ of mothers. Maternal educational status, occupation, and knowledge of initiation of complementary feeding were factors significantly associated with NEBF.

\section{Introduction}

Nonexclusive breastfeeding (NEBF) is defined as provision of food or fluids other than drugs, vitamins, and minerals to infants before the age of six months. Exclusive breastfeeding $(\mathrm{EBF})$ is vital and adequate for infants less than six months of age [1-3].

Globally, $60 \%$ of the 10.9 million infant and young child deaths annually occur due to inappropriate infant feeding practices and infectious disease where two-thirds of these deaths are attributable to suboptimal breastfeeding practices. No more than $35 \%$ of infants worldwide are exclusively breastfed during the first four months of life; complementary feeding frequently begins too early or too late, and foods are often nutritionally inadequate and unsafe $[4,5]$.
According to the Ethiopian Demographic and Health Survey 2011, the prevalence of nonexclusive breastfeeding before the age of 6 months was found to be $48 \%$; this has a great impact on the health and development of the child [6].

In low income countries like Ethiopia, it has been estimated that applying EBF can reduce less than five mortalities by $13 \%$ [7]. To strengthen the effort in reducing child mortality, the Ethiopian Ministry of Health (EMoH) had targeted an increase in the proportion of EBF for less than 6 months to $70 \%$ by 2015 [8].

To the best of our knowledge, no adequate studies were documented about non-EBF in the study area. Therefore, findings from this study will have a great significance in developing baseline information for further studies and for policy and program designers. 


\section{Methods and Materials}

2.1. Study Design. A community based cross-sectional quantitative study was employed at Gondar town from March 1 to 31,2014 , among mothers having infants 6-12 months old. Multistage sampling technique was employed. In the first stage from the twenty-four "kebeles" (the smallest subcity administration) six (3 rural and 3 urban) were selected using lottery method. Then individual households in the selected "kebeles" were selected using a systematic random sampling technique after identifying an initial starting household by use of a random number. The sample sizes were distributed proportionally to each of the "kebeles." In the case of more than one eligible participant in the household, lottery method was used to select only one. For eligible participant that was not found at home during data collection, the interviewers were revisiting the household three times at different time intervals and when interviewers failed to get the eligible participant, the household was registered as nonresponse. At the time of data collection mothers who were seriously ill and unable to respond and refuse to participate were excluded from the study.

2.2. Study Setting. The study was conducted at Gondar town from March 1 to 31, 2014. Gondar town is located at a distance of $720 \mathrm{~km}$ from the capital city Addis Ababa to the north direction. Administratively the town has 24 kebeles, 12 urban and 12 rural with an estimated total population of 267,959. According to Gondar Woreda Central Statistical Authority 2014 census conversion factor estimated mothers of reproductive age groups were 63,185 and children less than five years of age were 36,282 among which 7,423 were with age less than 12 months and 5,654 were aged from 6 to 12 months.

2.3. Sample Size Determination. Sample size was determined using single population proportion formula considering the following assumptions.

(1) Prevalence of $\mathrm{NEBF}=42.9 \%$ from study conducted in Jimma, south Ethiopia.

(2) $95 \% \mathrm{CI}(Z=1.96$ significant level).

(3) $5 \%$ margin of error.

(4) $10 \%$ nonresponse rate.

(5) Design effect of 2:

$$
n=\frac{\left(\mathbf{Z}_{\boldsymbol{\alpha} / 2}\right)^{2} \mathbf{p}(\mathbf{1}-\mathbf{p})}{d^{2}},
$$

where $n=$ sample size.

Finally the sample size was found to be $\mathbf{8 2 8}$.

\section{Study Variable}

(a) Dependent Variable. Nonexclusive breastfeeding before 6 months.

(b) Independent Variables. Sociodemographic and economic factors, obstetric and health care related factors, and knowledge and pattern of complementary feeding factors.
3.1. Data Collection Tools. Data were collected using pretested interviewer based questionnaire. The questionnaire was adapted from World Health Organization (WHO) and some modifications were made.

3.2. Data Processing and Analysis. Data were checked and cleaned for their completeness and entered using EPi-info version 3.5.1 and transferred to SPSS version 20.0 statistical software analysis. Univariate analyses were computed and presented by percentage. Binary logistic regression analysis was used. Explanatory variables with $P$ value $<0.2$ in bivariate logistic regression were entered into multivariate logistic regression to control possible confounding and for further analysis and variables having $P$ value of $<0.05$ were considered as significantly associated with the dependent variable.

3.3. Ethical Consideration. Ethical clearance was obtained from the Ethical Review Committee of Department of Nursing, University of Gondar. Letter of permission was secured from the Gondar town administration office and selected local community leaders.

\section{Result}

4.1. Sociodemographic Characteristics of the Study Population. A total of 828 mothers of children aged between 6 and 12 months were included in the study and interviewed from 6 kebeles, with the response rate of $100 \%$. The mean age of the mothers was 27.6 with S.D. \pm 5.44 . Majority of the respondents were from Amhara (763) (92.1\%) in ethnicity and $676(81.6 \%)$ were Orthodox Christian. Seven hundred nine (91.7\%) were married. The highest distribution of educational status of mothers was primary education (237) (28.6\%) and husbands were of secondary education (227) (27.4\%). More than half subcity residents' (343) (50.4\%) average monthly income was $\geq 1500 \mathrm{ETB}$ and that of urban residents (75) (51.0\%) was 1000-1500 ETB. Regarding occupational status, majority of urban mothers (119) (81.0\%) and husbands (135) (91.8\%) were farmers, but most subcity mothers (397) (58.3\%) were housewives and husbands (193) (28.3\%) were merchants (Table 1).

4.2. Obstetric and Health Care Related Factors of the Participants. Of all study participants, majority of mothers (805) (97.2\%) had antenatal care (ANC) follow-up, and 666 (80.4\%) were informed about complementary feeding during their ANC. Nearly half of mothers (405) (48.9\%) delivered their last child at governmental hospital. Five hundred seven $(61.2 \%)$ of mothers were delivered by nurses/midwives and only two $(0.2 \%)$ were attended by health extension workers (HEW). Six hundred eighty-six $(82.9 \%)$ of the mothers attended postnatal care (PNC) and 610 (73.7\%) mothers counseled about complementary feeding (CF) during their PNC visit (Table 2).

4.3. Knowledge and Pattern of Nonexclusive Breastfeeding. Among the study participants, about 266 (32.1\%), 237 (28.6\%), and $176(21.3 \%)$ of mothers fed water, cereal based 
TABLE 1: Sociodemographic and economic characteristics of study participants in Gondar town, northwest Ethiopia, 2014.

\begin{tabular}{|c|c|c|c|}
\hline Variable & Subcity (urban) $(n=681)$ & $\operatorname{Rural}(n=147)$ & Frequency $(N=828)$ \\
\hline \multicolumn{4}{|l|}{ Maternal age } \\
\hline 15-19 & $35(5.15 \%)$ & $8(5.4 \%)$ & $43(5.2 \%)$ \\
\hline $20-24$ & $144(21.1 \%)$ & $30(20.4 \%)$ & $174(21.0 \%)$ \\
\hline $25-29$ & $283(41.6 \%)$ & $51(34.7 \%)$ & $334(40.3 \%)$ \\
\hline $30-34$ & $142(20.9 \%)$ & $27(18.4 \%)$ & $169(20.4 \%)$ \\
\hline $35-39$ & $51(7.5 \%)$ & $23(15.6 \%)$ & $74(8.9 \%)$ \\
\hline $40-44$ & $23(3.4 \%)$ & $8(5.4 \%)$ & $31(3.7 \%)$ \\
\hline$\geq 45$ & $3(0.4 \%)$ & $0(0.0 \%)$ & $3(0.4 \%)$ \\
\hline \multicolumn{4}{|l|}{ Mother's ethnicity } \\
\hline Amhara & $648(95.2 \%)$ & $115(78.2 \%)$ & $763(92.1 \%)$ \\
\hline Oromo & $11(1.6 \%)$ & $0(0.0 \%)$ & $11(1.3 \%)$ \\
\hline Tigray & $17(2.5 \%)$ & $1(0.7 \%)$ & $18(2.2 \%)$ \\
\hline Others & $5(0.7 \%)$ & $31(21.1 \%)$ & $36(4.3 \%)$ \\
\hline \multicolumn{4}{|l|}{ Mother's religion } \\
\hline Orthodox & $536(78.7 \%)$ & $140(95.2 \%)$ & $676(81.6 \%)$ \\
\hline Muslim & $77(11.3 \%)$ & $7(4.8 \%)$ & $84(10.1 \%)$ \\
\hline Protestant & $17(2.5 \%)$ & $0(0.0 \%)$ & $17(2.1 \%)$ \\
\hline Others & $51(7.5 \%)$ & $0(0.0 \%)$ & $51(6.2 \%)$ \\
\hline \multicolumn{4}{|l|}{ Marital status } \\
\hline Single & $8(1.2 \%)$ & $0(0.0 \%)$ & $8(1.0 \%)$ \\
\hline Married & $624(91.6 \%)$ & $135(91.8 \%)$ & $759(91.7 \%)$ \\
\hline Divorced & $41(6.0 \%)$ & $12(8.2 \%)$ & $53(6.4 \%)$ \\
\hline Widowed & $8(1.2 \%)$ & $0(0.0 \%)$ & $8(1.0 \%)$ \\
\hline \multicolumn{4}{|l|}{ Maternal educational status } \\
\hline Unable to read and write & $129(18.9 \%)$ & $69(46.9 \%)$ & $198(23.9 \%)$ \\
\hline Read and write & $26(3.8 \%)$ & $27(18.4 \%)$ & $53(6.4 \%)$ \\
\hline Primary education & $201(29.5 \%)$ & $36(24.5 \%)$ & $237(28.6 \%)$ \\
\hline Secondary education & $162(23.8 \%)$ & $14(9.5 \%)$ & $176(21.3 \%)$ \\
\hline Technical/vocational & $113(16.6 \%)$ & $1(0.7 \%)$ & $114(13.8 \%)$ \\
\hline Higher education & $50(7.3 \%)$ & $0(0.0 \%)$ & $50(6.0 \%)$ \\
\hline \multicolumn{4}{|l|}{ Husband's education } \\
\hline Unable to read and write & $66(9.7 \%)$ & $40(27.2 \%)$ & $106(12.8 \%)$ \\
\hline Read and write & $30(4.4 \%)$ & $51(34.7 \%)$ & $81(9.8 \%)$ \\
\hline Primary education & $176(25.8 \%)$ & $45(30.6 \%)$ & $221(26.7 \%)$ \\
\hline Secondary education & $217(31.9 \%)$ & $10(6.8 \%)$ & $227(27.4 \%)$ \\
\hline Technical/vocational & $8(11.7 \%)$ & $1(0.7 \%)$ & $81(9.8 \%)$ \\
\hline Higher education & $112(16.4 \%)$ & $0(0.0 \%)$ & $112(13.5 \%)$ \\
\hline \multicolumn{4}{|l|}{ Family size } \\
\hline$<4$ & $593(87.1 \%)$ & $77(52.4 \%)$ & $670(80.9 \%)$ \\
\hline$\geq 4$ & $88(12.9 \%)$ & $70(47.6 \%)$ & $158(19.1 \%)$ \\
\hline \multicolumn{4}{|l|}{ Total number of children } \\
\hline $1-2$ & $587(86.2 \%)$ & $73(49.7 \%)$ & $660(79.7 \%)$ \\
\hline $3-4$ & 75 (11\%) & $53(36.1 \%)$ & $128(15.5 \%)$ \\
\hline$\geq 5$ & $19(2.8 \%)$ & $21(14.2 \%)$ & $40(4.8 \%)$ \\
\hline \multicolumn{4}{|l|}{ Family income } \\
\hline$<500$ ETB & $7(1.0 \%)$ & $0(0.0 \%)$ & $7(0.8 \%)$ \\
\hline 500-1000 ЕТВ & $205(30.1 \%)$ & $68(46.3 \%)$ & $273(33.0 \%)$ \\
\hline 1000-1500 ЕTВ & $126(18.5 \%)$ & $75(51.0 \%)$ & $201(24.3 \%)$ \\
\hline$\geq 1500$ ETB & $343(50.4 \%)$ & $4(2.7 \%)$ & $347(41.9 \%)$ \\
\hline
\end{tabular}


TABle 1: Continued.

\begin{tabular}{lccc}
\hline Variable & Subcity $($ urban $)(n=681)$ & Rural $(n=147)$ & Frequency $(N=828)$ \\
\hline Mother's occupation & & & \\
$\quad$ Governmental employee & $96(14.1 \%)$ & $1(0.7 \%)$ & $97(11.7 \%)$ \\
Farmer & $10(1.5 \%)$ & $119(81.0 \%)$ & $129(15.6 \%)$ \\
Merchant & $102(15.0 \%)$ & $9(6.1 \%)$ & $111(13.4 \%)$ \\
Daily laborer & $65(9.5 \%)$ & $4(2.7 \%)$ & $69(8.3 \%)$ \\
Housewife & $400(58.7 \%)$ & $14(9.5 \%)$ & $414(50 \%)$ \\
Others & $8(1.2 \%)$ & $0(0.0 \%)$ & $8(1.0 \%)$ \\
Husband's occupation & & & $213(25.7 \%)$ \\
Governmental employee & $112(31.1 \%)$ & $1(0.7 \%)$ & $165(19.9 \%)$ \\
Farmer & $30(4.4 \%)$ & $135(91.8 \%)$ & $203(24.5 \%)$ \\
Merchant & $193(28.3 \%)$ & $10(6.8 \%)$ & $160(19.3 \%)$ \\
Daily laborer & $159(23.3 \%)$ & $1(0.7 \%)$ & $87(10.5 \%)$ \\
Private employee & $87(12.8 \%)$ & $0(0.0 \%)$ & $828(100 \%)$ \\
\hline Total & $681(82.2 \%)$ & $147(17.8 \%)$ & \\
\hline
\end{tabular}

TABLE 2: Obstetric and health care related factors of participants in Gondar town, northwest Ethiopia, 2014.

\begin{tabular}{|c|c|c|c|}
\hline Variable & Category & Frequency $(n)$ & Percent (\%) \\
\hline \multirow{2}{*}{ Antenatal care } & Yes & 805 & 97.2 \\
\hline & No & 23 & 2.8 \\
\hline \multirow{2}{*}{$\begin{array}{l}\text { Informed complementary feeding at antenatal } \\
\text { care }\end{array}$} & Yes & 666 & 80.4 \\
\hline & No & 162 & 19.6 \\
\hline \multirow{5}{*}{ Place of birth of last child } & Home & 136 & 16.4 \\
\hline & Governmental hospital & 405 & 48.9 \\
\hline & Health center & 244 & 29.5 \\
\hline & Health post & 2 & 0.2 \\
\hline & Private hospital/clinic & 41 & 5.0 \\
\hline \multirow{5}{*}{ Delivery attendance } & Doctor & 182 & 22.0 \\
\hline & Nurse/midwife & 507 & 61.2 \\
\hline & Health extension workers & 2 & 0.2 \\
\hline & Traditional birth attendants & 49 & 5.9 \\
\hline & Relative/friend & 88 & 10.6 \\
\hline \multirow{2}{*}{ Attended postnatal care } & Yes & 686 & 82.9 \\
\hline & No & 142 & 17.1 \\
\hline \multirow{2}{*}{$\begin{array}{l}\text { Counseled about complementary feeding at } \\
\text { postnatal care }\end{array}$} & Yes & 610 & 73.7 \\
\hline & No & 218 & 26.3 \\
\hline \multirow{2}{*}{ Heard information about complementary feeding } & Yes & 778 & 94.0 \\
\hline & No & 50 & 6.0 \\
\hline
\end{tabular}

fluids, and cow milk before six months to their infants, respectively. Eighty-five (10.3\%) mothers provided family food and 77 (9.3\%) mothers fed powder milk to their infants during the first six months of age.

With regard to feeding utensils, 246 (29.7\%) of mothers used cup and spoon, 80 (9.7\%) of mothers used bottle nipple and both bottle nipple and cup, and 47 (5.7\%) of mothers used spoon only.

The reasons of mothers who practiced NEBF were as follows: there is inadequacy of breast milk (174) (21.0\%), advice from family 87 (10.5\%), they did not know exactly when to start EBF (17) (2.1\%), mothers believed that child before 6 months may be able to digest food (79) (9.5\%), and mothers did not have reasons (36) (4.4\%).

The sources of information of mothers about complementary feeding were from health centers (536) (64.7\%) followed by HEWs (321) (38.8\%), radios (320) (38.6\%), television (297) $(35.9 \%)$, and relatives (41) $(5.0 \%)$ and the rest were from CHW (23) (2.8\%).

4.4. Prevalence of Nonexclusive Breastfeeding. The results of the study revealed that about 393 (47.5\%) of mothers practiced 
nonexclusive breastfeeding to their infants during the first 6 months of age. Among these 310 (78.9\%) mothers were from subcity and the rest (83) (21.1\%) were urban kebele residents of Gondar town.

\subsection{Factors Associated with Nonexclusive Breastfeeding. Bivar-} iate analysis showed that there were statistically significantly associations between nonexclusive breastfeeding and maternal education, occupational status, ANC follow-up, delivery attendance, place of delivery, knowledge for CF time, PNC follow-up, child's sex, number of under five children, husband's educational status, occupational status, and residence.

However, in multivariate analysis only maternal education, mother's occupational status, and knowledge of time for initiation of complementary feeding were statistically associated with nonexclusive breastfeeding.

Mothers having an educational status of primary school (grades 1-8) $(\mathrm{AOR}=0.46$ [95\% CI: $0.30,0.71])$ were less likely practicing nonexclusive breastfeeding compared to mothers with no formal education. On the contrary governmental employed mothers were more likely practicing nonexclusive breastfeeding to infants within the first 6 months compared to housewife $(\mathrm{AOR}=2.55$ [95\% CI: 1.45, 4.46]) (Table 3).

\section{Discussion}

Exclusive breastfeeding for the first six months is proved as one of interventions to reduce infant morbidity and mortality [9]. However, nonexclusive breastfeeding (NEBF) during the first six months can decrease the full absorption of nutrients from breast milk and increase the risk of diarrhea and acute respiratory infections [3].

This study showed that $47.5 \%$ of mothers in Gondar town practiced NEBF to their infants within the first six months of age. This finding was in line with EDHS 2011 report (48\%), a study conducted in Bahir Dar (49.3\%). Whereas higher than the study conducted in Jimma Arjo (42.9\%) and Arba Minch Zuria woreda (44.4\%) [4, 10-12]. The similarity of this study to Bahir Dar study could be the use of nearly equal sample size with community based cross-sectional study design and sociocultural resemblance among society on infant feeding practices. The possible explanation for increased prevalence of NEBF compared to Jima Arjo and Arba Minch Zuria could be owing to large sample size.

It was also similar to the study conducted in Pakistan (46\%) but much higher than study conducted in West India (38.5\%), Nigeria (34.6\%), and West Tanzania (42\%) [13-16]. This might be due to sociocultural difference of the study subjects.

The finding of this study is also much lower than the study done in Nias Island, Indonesia (79\%) [17]. The highest prevalence in Nias Island could be the study design used, which was institutional based cross-sectional one, among mothers who were hospitalized to mildly wasted infants which may increase use of additional diet and the majority of respondents believed that an appropriate time for introducing complementary foods was between one and four months.

This study showed that maternal educational status had significant role in NEBF within the first 6 months. Mothers having primary school (54\%) and secondary and above educational status (45\%) were noted to decrease practice of NEBF within the first 6 months compared to those who had no formal educational status, respectively. This finding was supported by the study done in Mekele town which revealed that maternal educational level of high school and above was 2.36 more likely introducing timely additional diet compared to illiterates. In Eastern Uganda one research revealed that mothers with higher education were $50 \%$, protected to practice NEBF within the first 6 months $[18,19]$. It can be explained that improved maternal educational status enhances mothers' understanding and identification of the effects of nonexclusive breastfeeding before 6 months and empowers them to defend against external interferences and pressures.

Maternal occupation was found to be one of those factors that showed significant association with nonexclusive breastfeeding (NEBF) for infants during the first 6 months of age. In the current study governmental employees mothers 2.55 times and farmers 2.54 times more likely practicing NEBF compared to housewives. This finding was consistent with the studies done in Bahir Dar city [10] and Mekele town [19] which revealed a positive association between housewives and EBF practice compared to other occupations. The study done in Sri Lanka showed large number of housemaid mothers (64.7\%) exclusively breastfed their babies for 6 months compared to the working mothers (43.6\%) [20]. This might be due to the fact that housewife mothers get to stay longer with their newborn and would not be obliged like mothers who are working to wean early to go to work, so they may also breastfeed their newborn.

Maternal knowledge of CF time was also significantly associated with NEBF during the first 6 months. Mothers who had knowledge of CF time $\geq 6$ months were $93 \%$ protected to practice NEBF compared to knowledge of CF time $<6$ months. This finding was in agreement with study done in Jima Arjo which showed that mothers who had information about EBF to six months were less likely (57\%) to early introduce CF compared to those who had no information about EBF [19]. The study done in Arba Minch supported this study as mothers who had knowledge of EBF were 1.46 times more likely timely introducing complementary food compared to those who had no knowledge to six months [12]. This study was also supported by the study done in Kersa district, eastern Ethiopia, that showed that NEBF was 3.4 times more likely to be practiced by mothers whose knowledge about infant and young child feeding practices was low [21]. The decreased practice of NEBF among mothers who had knowledge of CF time $\geq 6$ months could be explained as awareness of mother about appropriate time of CF increased; the practice of $\mathrm{NEBF}$ within the first 6 months will be decreased.

\section{Conclusion}

In this study the prevalence of nonexclusive breastfeeding was $47.5 \%$. This was relatively higher than the prevalence found in some areas of Ethiopia and other developing countries. Therefore, this study revealed that nonexclusive breastfeeding practices are major public problems in Gondar 
TABLE 3: Factors associated with nonexclusive breastfeeding before 6 months, in Gondar town, northwest Ethiopia, 2014.

\begin{tabular}{|c|c|c|c|c|}
\hline \multirow{2}{*}{ Variable } & \multicolumn{2}{|c|}{ Nonexclusive breastfeeding within 6 months } & \multirow{2}{*}{$\begin{array}{l}\text { Crude odds ratio } \\
\qquad(95 \% \mathrm{CI})\end{array}$} & \multirow{2}{*}{$\begin{array}{c}\text { Adjusted odds ratio } \\
(95 \% \mathrm{CI})\end{array}$} \\
\hline & Yes $n(\%)$ & No $n(\%)$ & & \\
\hline \multicolumn{5}{|l|}{ Child's sex } \\
\hline Male & $168(42.2)$ & $212(55.8)$ & $0.79(0.60,1.03)$ & - \\
\hline Female & $225(50.2)$ & $223(49.8)$ & 1.00 & \\
\hline \multicolumn{5}{|l|}{ Number of under five children } \\
\hline 1 & $294(45.6)$ & $351(54.2)$ & 1.00 & \\
\hline$\geq 2$ & $99(54.1)$ & $84(45.9)$ & $1.41(1.01,1.96)$ & - \\
\hline \multicolumn{5}{|l|}{ Mother's education } \\
\hline No formal education & $149(59.4)$ & $102(40.6)$ & 1.00 & 1.00 \\
\hline Primary education & $82(34.6)$ & $155(65.4)$ & $0.36(0.25,0.52)^{* * *}$ & $0.46(0.30,0.71)^{* * *}$ \\
\hline Secondary education and above & $162(47.6)$ & $178(52.4)$ & $0.62(0.45,0.87)^{* *}$ & $0.55(0.35,0.87)^{* *}$ \\
\hline \multicolumn{5}{|l|}{ Husband's education } \\
\hline No formal education & $101(54.0)$ & $86(46.0)$ & 1.00 & \\
\hline Primary education & $100(45.2)$ & $121(54.8)$ & $0.70(0.48,1.04)$ & \\
\hline Secondary education and above & $192(45.7)$ & $228(54.3)$ & $0.72(0.51,1.01)$ & - \\
\hline \multicolumn{5}{|l|}{ Mother's occupation } \\
\hline Governmental employee & $59(60.8)$ & $38(39.2)$ & $2.09(1.33,3.28)$ & $2.55(1.45,4.46)$ \\
\hline Farmer & $78(60.5)$ & $51(39.5)$ & $2.06(1.38,3.08)$ & $2.54(1.58,4.09)$ \\
\hline Merchant & $48(43.2)$ & $63(56.8)$ & $1.02(0.67,1.56)$ & $0.83(0.49,1.40)$ \\
\hline Daily laborer & $28(40.6)$ & $41(59.4)$ & $0.92(0.55,1.54)$ & $0.85(0.45,1.60)$ \\
\hline Housewife & $180(42.7)$ & $242(57.3)$ & 1.00 & 1.00 \\
\hline \multicolumn{5}{|l|}{ Husband's occupation } \\
\hline Governmental employee & $107(50.2)$ & $106(49.8)$ & $1.82(1.09,3.05)$ & - \\
\hline Farmer & $97(58.8)$ & $68(41.2)$ & $2.58(1.38,3.07)$ & \\
\hline Merchant & $87(42.9)$ & $116(57.1)$ & $1.02(0.67,1.56)$ & \\
\hline Daily laborer & $71(44.4)$ & $89(55.6)$ & $0.92(0.55,1.54)$ & \\
\hline Private employee & $31(35.6)$ & $56(64.4)$ & 1.00 & \\
\hline \multicolumn{5}{|l|}{ Attended ANC visit } \\
\hline Yes & $376(46.7)$ & $429(53.3)$ & $0.31(0.12,0.79)$ & - \\
\hline No & $17(73.9)$ & $6(26.1)$ & 1.00 & \\
\hline \multicolumn{5}{|l|}{ Delivery attendant } \\
\hline Professional & $309(44.8)$ & $380(55.2)$ & $0.53(0.37,0.77)$ & - \\
\hline Nonprofessional & $84(60.4)$ & $55(39.6)$ & 1.00 & \\
\hline \multicolumn{5}{|l|}{ Attended PNC } \\
\hline Yes & $315(45.9)$ & $371(54.1)$ & $0.70(0.49,1.002)$ & - \\
\hline No & $78(54.9)$ & $64(45.1)$ & 1.00 & \\
\hline \multicolumn{5}{|l|}{ Knowledge for CF time } \\
\hline$<6$ months & $33(14.2)$ & $199(85.8)$ & 1.00 & 1.00 \\
\hline$\geq 6$ months & $402(67.4)$ & $194(32.6)$ & $0.08(0.05,0.12)$ & $0.07(0.04,0.10)$ \\
\hline \multicolumn{5}{|l|}{ Residence } \\
\hline Subcity & $310(45.5)$ & $371(54.5)$ & $0.64(0.45,0.92)$ & - \\
\hline Urban & $83(56.5)$ & $64(43.5)$ & 1.00 & \\
\hline
\end{tabular}


town. Maternal educational status, maternal occupation, and mother's knowledge of time of initiation for complementary feeding were the predictors of nonexclusive breastfeeding.

\section{Conflict of Interests}

The authors declare that there is no conflict of interests regarding the publication of this paper.

\section{Acknowledgments}

The authors would like to express their heartfelt thanks to all the study participants and data collectors; their thanks also go to University of Gondar for financial support.

\section{References}

[1] World Health Organization, "Complementary feeding: summary of guiding principles," Report of the Global Consultation 2001, World Health Organization, Geneva, Switzerland, 2002.

[2] Federal Ministry of Health and Family Health Department Ethiopia, National Strategy for Infant and Young Child Feeding, Federal Ministry of Health, Family Health Department Ethiopia, Addis Ababa, Ethiopia, 2004.

[3] PAHO/WHO, Guiding Principles for Complementary Feeding of the Breastfed Child, Division of Health Promotion and Protection, Food and Nutrition Program, Washington, DC, USA, Pan American Health Organization, World Health Organization, Geneva, Switzerland, 2003.

[4] Central Statistical Agency and ORC Macro, Ethiopia Demographic and Health Survey 2011, Central Statistical Agency, Addis Ababa, Ethiopia; ORC Macro, Calverton, Md, USA, 2011.

[5] UNICEF and World Health Organization, Global Strategy for Infant and Young Child Feeding, UNICEF and World Health Organization, Geneva, Switzerland, 2003.

[6] World Health Organization, Infant and Young Child Feeding: Model Chapter for Textbooks for Medical Students and Allied Health Professionals, World Health Organization, Geneva, Switzerland, 2009.

[7] G. Jones, R. W. Steketee, R. E. Black, Z. A. Bhutta, and S. S. Morris, "How many child deaths can we prevent this year?" The Lancet, vol. 362, no. 9377, pp. 65-71, 2003.

[8] Federal Ministry of Health, Health Sector Development Program IV Woreda Based Annual Core Plan, Federal Ministry of Health, Addis Ababa, Ethiopia, 2010.

[9] F. Ladomenou, J. Moschandreas, A. Kafatos, Y. Tselentis, and E. Galanakis, "Protective effect of exclusive breastfeeding against infections during infancy: a prospective study," Archives of Disease in Childhood, vol. 95, no. 12, pp. 1004-1008, 2010.

[10] A. M. Seid, M. E. Yesuf, and D. N. Koye, "Prevalence of Exclusive Breastfeeding Practices and associated factors among mothers in Bahir Dar city, Northwest Ethiopia: a community based cross-sectional study," International Breastfeeding Journal, vol. 8, no. 1, article 14, 2013.

[11] D. Tamiru, D. Aragu, and T. Belachew, "Introduction of complementary foods to infants within the first six months and associated factors in rural communities of jimma arjo," International Journal of Nutrition and Food Sciences, vol. 2, no. 2, pp. 77-84, 2013.
[12] D. Tamiru and S. Mohammed, "Maternal knowledge of optimal breastfeeding practices and associated factors in rural communities of Arba Minch Zuria," International Journal of Food Sciences and Nutrition, vol. 2, no. 3, pp. 122-129, 2013.

[13] S. P. Sapna, A. H. Ameya, S. P. Rooma, P. Aarti, A. K. Rashid, and K. A. Narayan, "Prevalence of exclusive breastfeeding and its correlates in an urban slum in Western India," International Journal of Science Medicine \& Education, vol. 3, no. 2, pp. 14-18, 2009.

[14] S. Ali, S. F. Ali, A. M. Imam, S. Ayub, and A. G. Billoo, "Perception and practices of breastfeeding of infants 0-6 months in an urban and a semi-urban community in Pakistan: a crosssectional study," Journal of the Pakistan Medical Association, vol. 61, no. 1, pp. 99-104, 2011.

[15] A. N. Maduforo, C. U. Nnaemeka, and N. Obiakor-Okeke, "The practice of exclusive breastfeeding by lactating women in Owerri metropolis, Imo State, Nigeria," Global Advanced Research Journal of Medicine and Medical Sciences, vol. 2, no. 1, pp. 13-19, 2013.

[16] T. E. Nkala and S. E. Msuya, "Prevalence and predictors of exclusive breastfeeding among women in Kigoma region, Western Tanzania: a community based cross-sectional study," International Breastfeeding Journal, vol. 6, no. 1, article 17, 2011.

[17] D. A. Inayati, V. Scherbaum, R. C. Purwestri et al., "Infant feeding practices among mildly wasted children: a retrospective study on Nias Island, Indonesia," International Breastfeeding Journal, vol. 7, article 3, 2012.

[18] I. M. S. Engebretsen, H. Wamani, C. Karamagi, N. Semiyaga, J. Tumwine, and T. Tylleskär, "Low adherence to exclusive breastfeeding in Eastern Uganda: a community-based cross-sectional study comparing dietary recall since birth with 24-hour recall," BMC Pediatrics, vol. 7, article 10, 2007.

[19] A. Shumey, M. Demissie, and Y. Berhane, "Timely initiation of complementary feeding and associated factors among children aged 6 to 12 months in Northern Ethiopia: an institution-based cross-sectional study," BMC Public Health, vol. 13, article 1050, 2013.

[20] M. L. Pathirathna, "Exclusive breast feeding practice in gangawatakoralaya $\mathrm{MOH}$ area, Sri Lanka," International Journal of Scientific and Research Publications, vol. 4, no. 2, 2014.

[21] G. Egata, Y. Berhane, and A. Worku, "Predictors of nonexclusive breastfeeding at 6 months among rural mothers in East Ethiopia: a community-based analytical cross-sectional study," International Breastfeeding Journal, vol. 8, no. 1, article 8, 2013. 


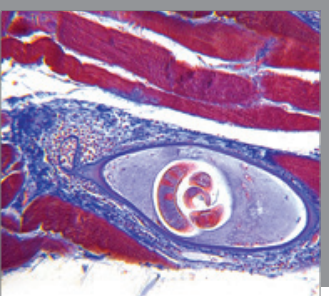

Gastroenterology

Research and Practice
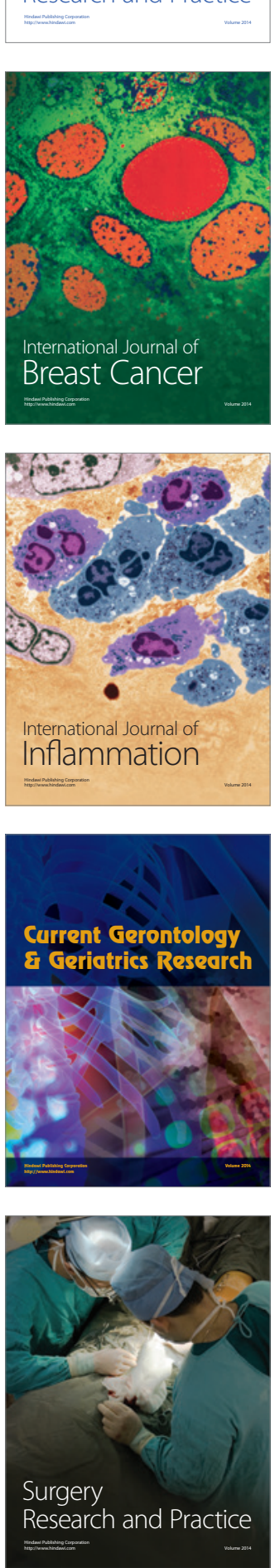

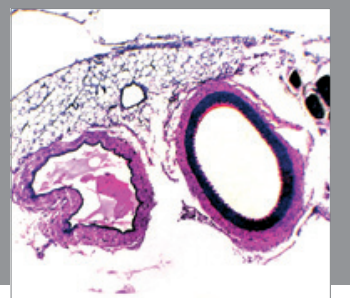

International Journal of Hypertension
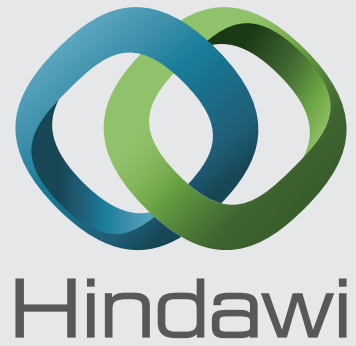

Submit your manuscripts at http://www.hindawi.com
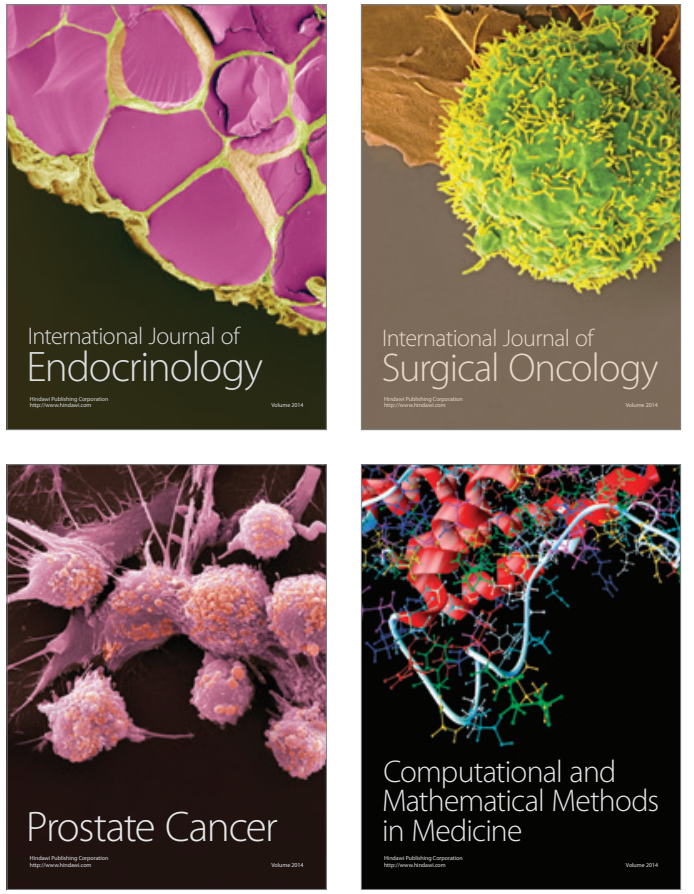
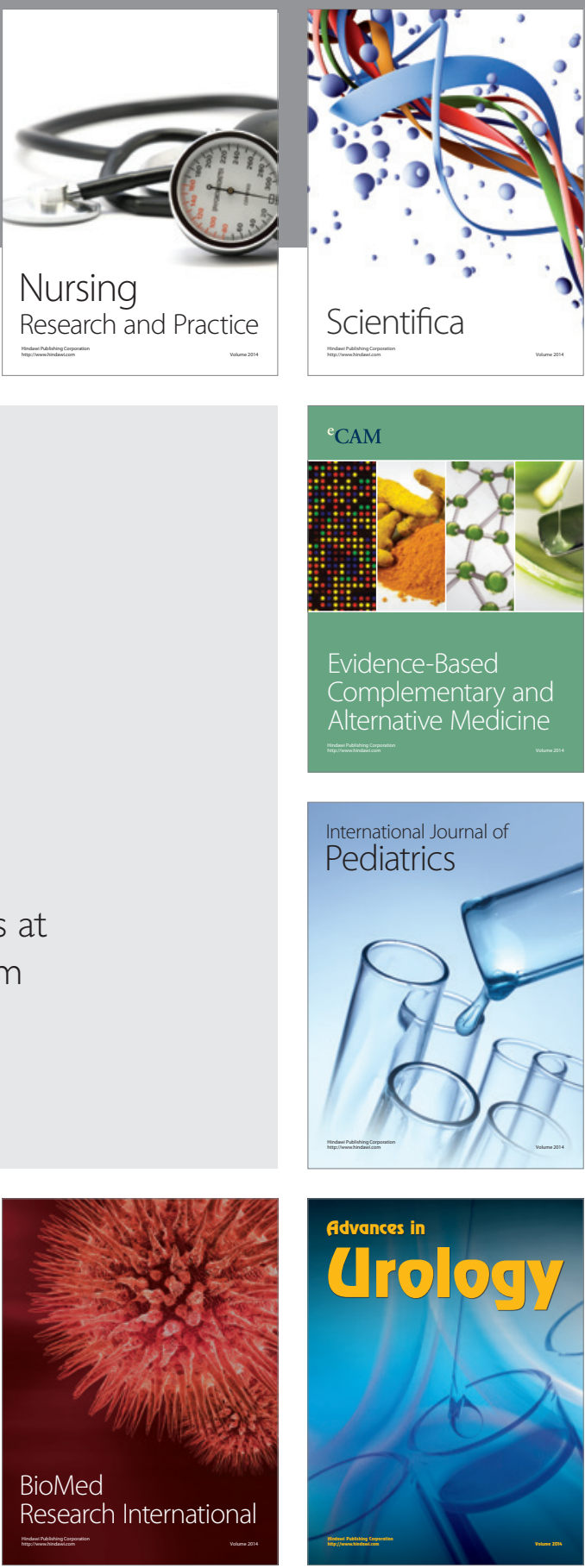

Nursing

Research and Practice

Scientifica

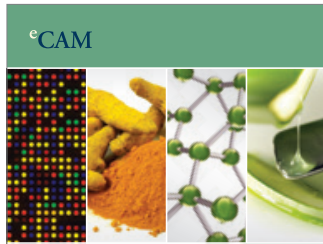

Evidence-Based

Complementary and Alternative Medicine
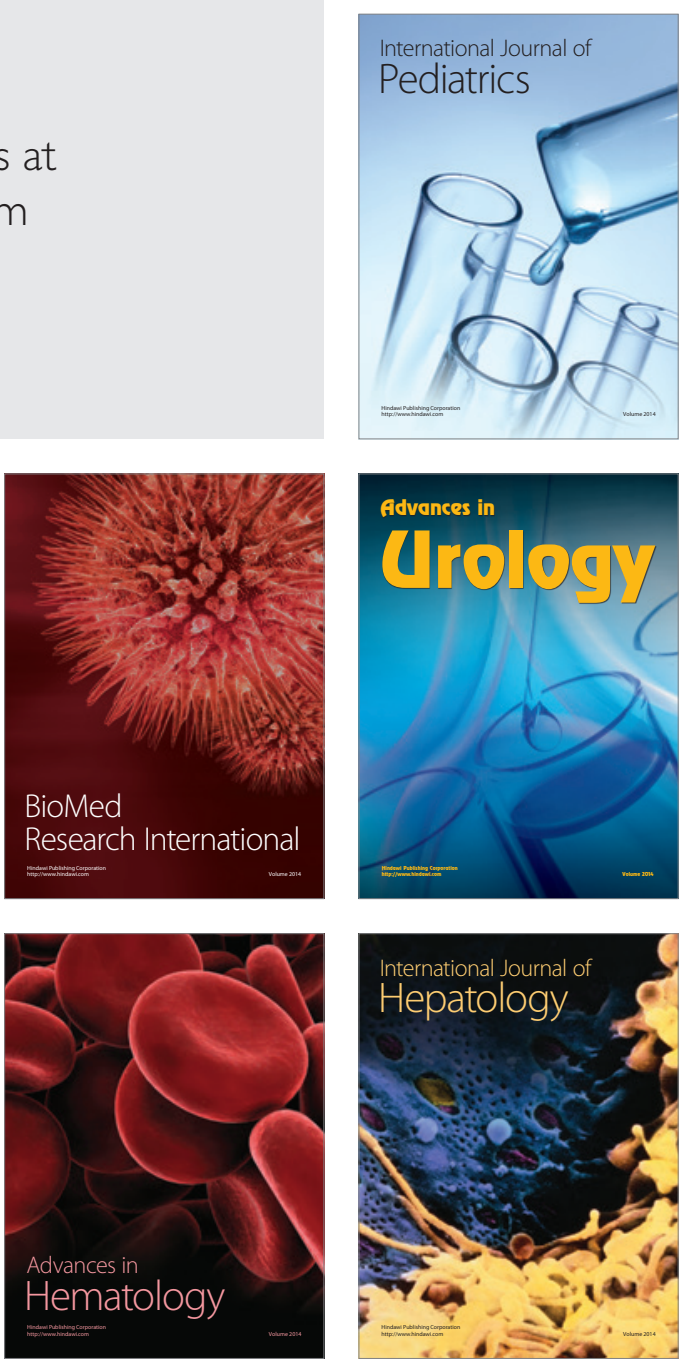